\title{
«Historia är något som konstrueras, det här är ett val» - om kritisk granskning i danshistorieundervisning \\ Saga Samuelson
}

\section{ABSTRAKT}

Den här artikeln undersöker och diskuterar hur danslärare vid gymnasieskolans estetiska program förhåller sig till undervisning i danshistoria inom kursen Dansteori, med fokus på skrivningarna om att eleverna ska utveckla en förmåga att kritiskt granska olika danshistorieskrivningar. Undersökningen bygger på intervjuer och öppna enkäter, och resultatet har analyserats kvalitativt i relation till historiografiska och normkritiska perspektiv. Studien visar att ett historiografiskt perspektiv är viktigt för hur lärare pratar om ämnet, men däremot inte i samma fokus när det kommer till vad de anser är det viktigaste för eleverna att ha med sig. Där står allmänbildning och elevernas förmåga att relatera sitt eget dansande till ett historiskt sammanhang i centrum. Det normkritiska perspektivet visar sig främst i lärarnas positionering av sig själva, men som jag förstår det ligger den kritiska granskningen ändå främst inom normen snarare än som medel för att se utanför den västerländska lådan. Nästa utmaning för oss lärare är därför att inte bara granska betingelserna för hur historia skapas, utan också ifrågasätta och förändra de strukturer som skapar kunskap.

\section{ABSTRACT}

This article examines and discusses how teachers at upper secondary school relate to teaching dance history within the course Dance Theory, focusing on the aim that students critically examine various dance history writings. The study uses interviews and open-ended questionnaires, and the material has been analysed qualitatively and discussed in relation to historiographical and norm-critical perspectives. The study shows that a historiographic perspective is important to teachers when they describe their teaching but less important when describing what they think students should gain from their studies. Instead, a general knowledge of dance history and an ability to connect one's dancing to a historical context are central. The norm-critical perspective is manifested mainly in the teachers' positioning of themselves, but as I understand it, the critical examination primarily lies within the norm rather than providing a means of looking outside the Western box. The next challenge is therefore to not only review the conditions in which history is created but also question and change the structures that create knowledge. 


\section{«Historia är något som konstrueras, det här är ett val» - om kritisk granskning i danshistorieundervisning}

Saga Samuelson

En av dessa kurser är Dansteori, där jag förväntas undervisa om historiska epoker, genrer, stilar, förändringsprocesser och estetiska förhållningssätt till dans samt utveckla mina elevers förmåga att kritiskt granska olika danshistorieskrivningar. Danshistorieundervisningen på min lärarutbildning var begränsad till en kurs inom vald genre. I den skulle vi också hinna lära oss hur man undervisar danshistoria.

Jag känner mig inte rustad. Min upplevelse är också att många andra lärare - både blivande och redan verksamma - uttrycker att de saknar kunskaper när det kommer till både innehåll och metoder för att undervisa kursen Dansteori. Kursen saknar läromedel, officiellt arbetsmaterial och bedömningsanvisningar, och det är ofta en, ensam lärare på varje skola som undervisar kursen vilket försvårar kollegialt lärande. Det finns ingen forskning kring danshistorieundervisning i en svensk kontext, och även internationellt finns mycket få empiriska undersökningar. Därför är jag intresserad av att undersöka hur danslärare förhåller sig till undervisning av danshistoria i kursen Dansteori.

\section{Kritisk granskning av danshistoria}

Den här artikeln handlar alltså om danshistoria $\mathrm{i}$ ett danspedagogiskt sammanhang, och fokuserar på undervisningen av danshistoria inom kursen Dansteori. Dansteori är en av de obligatoriska kurserna i den svenska gymnasieskolans estetiska program med inriktning dans. Dansteori beskrivs i ämnesplanen som ett tvärvetenskapligt ämne där eleverna med hjälp av begrepp, teorier och metoder från dans- och kulturvetenskap ska lärasig att tolka och förstå dans som en del av det estetiska, sociala, politiska och kulturella sammanhanget (Skolverket u.åa). Det historiska perspektivet genomsyrar nästan alla formuleringar i kursens syfte, och två av målen handlar specifikt om danshistoria: eleverna ska utveckla kunskaper om historiska epoker, genrer, stilar, förändringsprocesser och estetiska förhållningssätt till dans samt utveckla förmåga att kritiskt granska olika danshistorieskrivningar och avgränsningar som används inom dansområdet (Skolverket u.åa.a). Dessa två mål relaterar till två olika aspekter av historieämnet: dels själva innehållet och dels hur detta innehåll berättas. En grundbult i att förstå historia är nämligen att kunna göra skillnad mellan det förflutna, alltså det som hänt, och bistoria, alltså hur vi skapar berättelser och kunskap om det som har hänt. Kursen Dansteori handlar alltså inte bara om att lära sig en historisk genreöversikt med fokus på några viktiga koreografer och verk, utan också om att lära sig att kritiskt granska, värdera och diskutera konsekvenserna av olika historieskrivningar (Skolverket u.åa).

Syftet med artikeln är att undersöka och diskutera hur lärare i gymnasieskolan arbetar med ämnesplanens mål att «utveckla förmåga att kritiskt granska olika danshistorieskrivningar och andra avgränsningar och indelningar som används i dansområdet» (Skolverket u.å.a). Artikeln ger också förslag på möjliga sätt att fördjupa och utveckla arbetet med kritisk granskning, främst i förhållande till det västerländska perspektivets dominans. 


\section{Kritiskt tänkande - komplex företeelse}

Kritisk granskning, eller kritiskt tänkande, är inte bara ett mål inom kursen Dansteori utan också ett tydligt uttalat mål för hela den svenska skolan. I läroplanen för gymnasieskolan står det bland annat att «[e] leverna ska träna sig att tänka kritiskt, att granska fakta och förhållanden och att inse konsekvenserna av olika alternativ» (Gy11 2011, 7). Kritiskt tänkande är dock en komplex företeelse. Det finns ingen enhetlig och samstämmig definition, utan en rad olika definitioner som ofta kommer med långa listor av preciseringar (Larsson 2013, 30-32). Skolverket har heller ingen egen definition, men lyfter konsekvent förmågan att «kritiskt granska och värdera information» som central i skolans verksamhet (ex. Skolverket 2020). Larsson framhåller att den empiriska forskningen och vetenskapliga diskussionen kring kritiskt tänkande i den svenska skolan är begränsad (Larsson 2013, 14), och Nygren et. al. (2018) visar att kritiskt tänkande i den svenska skolan innebär olika saker inom olika ämnen. Att kritiskt granska kan alltså göras på många olika sätt, och den här artikeln utgår därför från frågeställningen: Vilka förhållningssätt och perspektiv lyfter danslärare fram för kritisk granskning av olika danshistorieskrivningar inom kursen Dansteori?

\section{Metod och material}

Arbetet baseras på intervjuer och enkäter med gymnasielärare i dans i Sverige. Förfrågan om medverkan skickades ut till alla estetiska program med inriktning dans i landet, och totalt har 12 lärare bidragit till studien: tre i form av intervjuer (varav två intervjuades tillsammans och en individuellt) och nio i form av webbaserade enkäter med öppna svarsalternativ.

Tiden lärarna har arbetat på estetiska programmet spänner mellan en termin och 24 år. Sex av lärarna har arbetat över 15 år, tre har arbetat mellan fem och 15 år och tre kortare än två år på estetiskt program. Tiden de har undervisat kursen Dansteori varierar mellan en termin och sedan införandet av kursen 2011. Tio av lärarna har lärarlegitimation. De två lärare som saknar legitimation är utbildade danspedagoger, varav en läser VAL nu.

Materialet har analyserats med hjälp av kvalitativ analys. Jag har utgått från Lantz (2013) modell, men även tagit inspiration från Bryman (2018) och Lundman \& Hällgren Graneheim (2017). Lantz delar upp analysprocessen i tre steg: datareduktion, att bilda dimensioner som avspeglar innehållet och att söka mönster. Det första steget innebär att begränsa datamängden med utgångspunkt i frågeställningen, det andra steget innefattar att koda materialet och organisera det i teman och det tredje steget handlar om att fördjupa förståelsen för resultatet genom att relatera det till teoretiska begrepp och modeller (Lantz 2013, 145-162).

\section{Historiografiska och normkritiska perspektiv}

Lärarnas svar diskuteras $\mathrm{i}$ artikeln $\mathrm{i}$ relation till bistoriografiska och normkritiska perspektiv. Dessa två perspektiv för kritisk granskning är framträdande i mitt material, och finns också representerade i forskningslitteraturen om danshistorieundervisning.

Historiografi innebär studiet av historikers metoder för att skriva historia, och handlar om att medvetandegöra premisserna för historieskrivning och historikerns roll i skapandet av historiska berättelser. I litteraturen om danshistorieundervisning är historiografi som metod mycket framträdande, och många författare förespråkar en undervisning som genom att synliggöra hur de historiska berättelserna skapas ger utrymme att ifrågasätta befintliga historieskrivningar (ex. Adshead-Lansdale \& Layson 1994, Carter 2004a, Carter 2004b, Tomko 2005, Carter 2007, Huxley 2012, Morris \& Nicholas 2018a). Det historiografiska perspektivet belyser hur lärarna i min undersökning synliggör skillnaden mellan det 
förflutna som sådant och våra berättelser om det förflutna, vilket alltså krävs enligt ämnesplanen.

Att medvetandegöra premisserna för historieskrivning kan också göras med ett maktkritiskt syfte. Termen critical dance pedagogy har exempelvis myntats av McCarthy-Brown (2017) för dansundervisning som underööker hur maktsystem skapas och upprätthålls inom dansen. Critical dance pedagogy anknyter till det svenska begreppet normkritik i det att de båda uppmanar elever och lärare att ställa frågor kring de maktstrukturer som gör saker värdefulla och begripliga, och att sedan utmana dessa strukturer. Skolverket (2014) lyfter fram normkritiska perspektiv som en metod för att förebygga diskriminering och kränkande behandling, och normkritik utgör en del av skolans obligatoriska värdegrundsarbete. Det normkritiska perspektivet belyser hur lärarna i min undersökning tar sig an danshistorieundervisningen ur ett mer politiskt, maktkritiskt perspektiv.

\section{Balansen mellan begripliga berättelser och verklighetens virrvarr. \\ Vem åger historien?}

Lärarna i min studie ger många exempel på hur de arbetar för att anlägga ett historiografiskt perspektiv på undervisningen, och stort fokus ligger på att ställa frågor som synliggör historieskrivningens förutsättningar. Flera lärare lyfter fram att de i sin undervisning betonar att historia är något som konstrueras, och att det vi ser som sanningar idag kan förändras genom vidare forskning. En lärare skriver exempelvis att hen är noggrann med att poängtera att «historien hela tiden förnyas och är under ständig utveckling». En annan berättar att hen «försöker vara transparant med att historia är något som konstrueras, det här är ett val». Ett par lärare lyfter fram att forskningsläget påverkar kunskapsläget: «att det vi sett som sanningar kan förändras genom vidare forskning» och »[a]tt vi får hålla oss öppna till att det vi läser i danshistorien kan förändras om det görs en mer ingående och nyanserad forskning $\mathrm{i}$ framtiden».

Något som hör samman med det faktum att historia konstrueras är att historien inte är objektiv. Flera av lärarna framhåller att det är viktigt att förmedla till eleverna att historien påverkas av den som berättar den, och att den därför måste granskas. «Berättelsen är alltid kontaminerad» skriver en lärare, och poängterar att det därför är «viktigt att hitta källan (skrivaren) och syftet med att just detta är skrivet». En annan lärare skriver att «historien färgas av den som berättar den» och att det därför är viktigt med kritisk källgranskning. En lärare skriver: «jag tänker att det handlar om hur danshistorien skrivs, av vem, varför o.s.v. Vad finns nedtecknat och vad finns inte det? Vems danshistoria är det som berättas? Varför anses vissa koreografer ha större betydelse än andra? Vem har tolkningsföreträde på historien?« Ordet tolkningsföreträde signalerar ett maktperspektiv på frågan om vem som skriver historien. Detta återfinns även hos andra lärare: «Vem är det som äger historien, vem har skrivit den?« frågar sig en, och en annan pratar om historieskrivning utifrån begreppet eurocentrism: «Jag har i mitt arbete försökt att tydliggöra och diskutera eurocentrism med mina elever. Vem skriver historia och från vilket perspektiv?»

\section{Perspeltivet fårgar historien}

Perspektiv är ett ord som förekommer flitigt i mitt material. En lärare skriver exempelvis att «i mina föreläsningar försöker jag belysa att det finns olika perspektiv och att vi inte alltid vet om det vi tar del av är sant eller riktigt» och en annan att «historien är komplex och ska kunna förstås utifrån flera perspektiv och inte utifrån en bestämd historisk sanning som formar vårt tänkande». Ordet perspektiv används på många olika sätt i mitt material: det kan innebära alltifrån någons oreflekterade utgångspunkt (vem man «är») till en medveten analytisk hållning (ex. 
att anlägga ett genusperspektiv). De olika perspektiven kan också påverka historieskrivningarna i olika led: när historien «händer», när den dokumenteras, när den bearbetas i form av forskning eller historiska berättelser och när den används av lärare och elever i undervisningen. Alla dessa steg kan vara färgade, eller kontaminerade som läraren uttryckte det, av olika perspektiv. Perspektivtagande, eller multiperspektivitet, är en viktig komponent i kritiskt tänkande inom historia (Nygren et. al. 2019) och min uppfattning är att perspektiv är ett begrepp som lärarna anser vara mycket användbart för att förtydliga de många lager som skiljer det förflutna från historieskrivningen. Användbart, men också - som vi märker - mycket mångfacetterat.

\section{Vikten av källkritik och kritiska frågor}

Ett annat begrepp som återkommer är källkritik, och då oftast som övergripande begrepp för kritisk granskning av olika danshistorieskrivningar. Två av lärarna presenterar exempelvis först en rad synliggörande frågor (av typen: vem har skrivit detta och varför) och sammanfattar sedan med: «[1]ite som källkritik för danshistoria» och «[j] ag kan se det lite grand som vi idag pratar om källkritik». En lärare skriver att arbetet med olika danshistorieskrivningar innebär «kritisk källgranskning» och en annan att det innebär «att inte ta en beskrivning som en självklar sanning. Att förhålla sig källkritisk». Källkritik används alltså av dessa lärare som övergripande begrepp för, eller synonymt med, kritisk granskning av olika danshistorieskrivningar.

Att förhålla sig källkritisk till historieskrivningar, att anlägga ett bistoriografiskt perspektiv, är alltså ett av de förhållningssätt för att kritiskt granska olika danshistorieskrivningar som framkommer i mitt material. Lärarna presenterar en mängd olika synliggörande frågor som de framhåller som viktiga för att eleverna ska kunna kritiskt granska olika his- torieskrivningar. Lärarnas kritiska frågor till danshistorieskrivningen ligger i linje med den vetenskapliga debatten kring danshistorieundervisning. Huxley konstaterar exempelvis att «there has been a shift in emphasis from a study based on traditional dance historical methods to one where a critical perspective is assumed» $(2012,281)$. Även andra forskare argumenterar för att danshistoria kan göras relevant och värdefull för studenter genom ett vetenskapligt förhållningssätt, exempelvis Carter (2004a, 2004b), Järvinen (2009), Randall (2009) m.fl. Carter (2007) har också i en inventering av 32 danshistoriekurser från huvudsakligen brittiska universitet kommit fram till att danshistoria har en viktig plats i dessa utbildningar, och att det också finns en ökande medvetenhet om historiska metoder och frågeställningar i undervisningen. Detta syns alltså också i min undersökning.

\section{Basen fo̊rst - sen kritisk granskning}

I min undersökning framkommer dock också en märkbar konflikt mellan tiden till förfogande, faktainnehållet och de kritiska perspektiven, och i den konflikten prioriteras innehållet framför den kritiska granskningen.

För att kunna anlägga ett vetenskapligt perspektiv och ställa kritiska frågor krävs «faktakunskaper» om vad som har hänt, och i mitt material finns en tendens att se på danshistorien som ett «rent» innehåll som sedan kan analyseras, diskuteras och kritiskt granskas: flera lärare menar att man först behöver lägga en grund som eleverna sedan kan lyfta sig från. En lärare beskriver sin undervisning i danshistoria som en tvåstegsraket där hen först avsätter ett par veckor för att lägga en danshistorisk grund, som sedan används som utgångspunkt för uppgifter som utgår från kursens olika centrala innehåll: "Min kronologiska 'rena' danshistoria handlar om det som ska beskrivas som starten för de olika genrerna och ska ge en förförståelse för grunden av hur dansen ser ut idag [...] [N]är jag 
sedan fortsätter in i andra uppgifter som kan beröra något från vår danshistoria så ligger fokus på annat än historia.«En annan lärare säger: «Jag ser det också som att Dansteori väldigt mycket är en process, och lite som i steg - att man först får den här banken, och sen kunna lyfta ifrån det. «Samma lärare säger också att när «eleverna har fullt sjå med att få in faktan» är det svårt att hitta de kritiska glasögonen: utan en ordentlig bas är det svårt att lyfta blicken mot de kritiska perspektiven. Tanken om den «rena» danshistorien går på tvärs mot tanken om att all historisk information är färgad, och att det inte finns några neutrala berättelser. Jag återkommer till denna konflikt snart.

\section{Bredd framfo̊r djup}

Många av lärarna påpekar att kursens innehåll upplevs som för stort i förhållande till tiden. «En komplex kurs som borde vara dubbelt så stor» skriver en lärare, och en annan att «den största utmaningen är att hinna med alla moment i kursen på ett fördjupat sätt. Jag upplever kursinnehållet i Dansteori som stort i förhållande till kurspoängen». Kursens stora innehåll tvingar fram prioriteringar, och på frågan om vad lärarna tycker är det viktigaste eleverna ska få med sig från undervisningen dominerar innehållet framför processen: «Jag tycker det viktigaste är att eleverna får en översikt och en helhetsbild av västerländsk dansscenkonsthistoria» skriver en av lärarna. «Jag tror att det är bredden av danshistorien som är viktigast» skriver en annan. Att eleverna får en bred kunskap om olika genrer och deras utveckling samt dansens koppling till samhället, och en förståelse för varför dansen ser ut som den gör idag, anges av de flesta lärare som det allra viktigaste.

I forskningslitteraturen kan ett mönster urskiljas där frågan om varför danshistoria besvaras med att studenterna ska fă en förståelse för sin samtid, och frågan om bur detta ska åstadkommas besvaras med kritiska perspektiv och historievetenskapliga metoder
(Carter 2004b, Carter 2007, Järvinen 2009, Randall 2009, Huxley 2012). En liknande fördelning märks i min undersökning, där de kritiska perspektiven är framträdande i hur lärarna pratar om danshistorieundervisningen men däremot inte framhålls som det viktigaste för eleverna att fă med sig. De kritiska perspektiven fungerar som en metod, men inte ett mål.

I mitt material kan man också urskilja en frustration över att inte hinna fördjupa och nå hela vägen till den kritiska granskningen. En av lärarna skriver att «utmaningen är att inte känna att de kanske inte fătt med allt som förväntas i kursen», och medger därmed att hen inte alltid hinner arbeta med alla kursens delar såsom hen önskar. En annan skriver att «om jag ska vara ärlig har jag nog snarare fokuserat på bredd och allmänbildning inom danshistoria än djup och danshistorieskrivning». Även Carter (2007) konstaterar att brist på tid är den största utmaningen i utvecklandet av elevernas kritiska tänkande i danshistoria, och också att det är svårt att främja kritiskt tänkande när studenterna är upptagna med så mycket nytt innehåll. Lärarna i min studie bekräftar detta, och när tiden är knapp så prioriteras allmänbildningen.

\section{En svår balansgång}

Att hitta balansen mellan innehåll och kritiska perspektiv är en utmaning i all undervisning. Hur ska eleverna kunna kritiskt granska något de inte har grundläggande faktakunskaper om? Hur gör vi för att förmedla stora mängder «stoff» utan att hamna i memorerande minneshistoria? Det finns en pedagogisk konflikt mellan att presentera tydliga, lättbegripliga berättelser, och att samtidigt göra eleverna öppna för tolkningar och motsägelser. Det finns historiedidaktiker som menar att narrativet är den effektivaste pedagogiska metoden för att skapa förståelse för historien (ex. Karlsson 2014), men samtidigt höjs inom historievetenskapen ett varnande finger mot hur narrativet förenklar och stänger ute andra berättelser (ex. Hammergren 2009, Carter 2007). Det 
är som synes ingen lätt balansgång, och det är tydligt i min undersökning att det finns en konflikt mellan faktainnehållet och de kritiska perspektiven. Det finns hos vissa lärare en uppfattning om att det historiska innehållet kan undervisas frikopplat från den kritiska granskningen, och hos de flesta lärare prioriteras innehållet framför den kritiska granskningen.

\section{Problemet med det}

\section{våsterlåndska perspektivet}

Normkritisk pedagogik går ut på att synliggöra normer för att sedan kunna förändra dem. En viktig del av den normkritiska pedagogiken är att granska sin egen position och bli varse sin roll som medskapare av normer, för att sedan kunna bryta detta mönster (Sörensdotter 2010). I min undersökning finns många exempel på hur lärarna öppnar upp för kritisk granskning genom att problematisera sin egen roll i relation till undervisningens innehåll. Detta är särskilt tydligt i förhållande till det västerländska perspektiv de representerar.

Som tidigare nämnts använder en av lärarna begreppet eurocentrism för att belysa att danshistorien ofta har ett västerländskt perspektiv. En annan lärare framhåller att det som undervisas är ett val som läraren gör och måste stå för, och poängterar att det läraren har fătt med sig från sin utbildning påverkar hur undervisningen ser ut, särskilt i relation till det västerländska perspektivet: «Vi kom in lite på vad som hände i andra delar av världen vid den här tiden, och då: 'jag vet inte riktigt'. Då tänkte jag mycket på vad jag har fått med mig. « En annan lärare säger att hen är noga med att «medvetandegöra dem [eleverna, min anm.] om att det här är vem jag är, det här är en vit västerländsk utgångspunkt». Samma lärare påpekar att även när de läser om danser från den afrikanska diasporan så blir det ur ett västerländskt perspektiv: «för man tittar ju med den koloniala blicken, triangelhandeln, det är någonstans där 'det börjar', fast man känner att det höll ju på ganska länge innan dess». En annan lärare säger att «det är lätt att man hamnar i det europeiska och det som hänt i USA», men att «det är viktigt att jag är medveten om det och att jag utmanar det och ser till att det inte enbart blir det de får».

Några av lärarna problematiserar också själva de kritiska perspektiven och deras tidsbundenhet. En lärare säger att «de kritiska perspektiven, de ändrar ju sig hela tiden, så där får man hålla sig a jour med sin samtid» och en annan frågar sig varför vi ens har genusglasögon: «All analys - även analysverktyg har en historia. Varför har vi ens genusglasögon? När blev det en fråga? [...] Så varför tar 'vi' emot det som berättas på just det här sättet? « En lärare skriver att hen försöker «uppmuntra [s] ina elever att vara medvetna om vilken förförståelse de har och hur det påverkar hur de tolkar materialet». Dessa uttalanden belyser det faktum att det inte bara är historieskrivningen som är «kontaminerad», utan att också lärarna och eleverna som användare av historien är färgade av sina erfarenheter och det samhälle de lever i, vilket i sin tur påverkar hur de tar emot historiska berättelser.

En viktig del inom den normkritiska pedagogiken är alltså att läraren granskar sin egen position och kunskapssyn. Sörensdotter (2010) skriver däremot att denna reflektion inte är särskilt vanlig i ett lärarsammanhang. I min undersökning framkommer dock att många av lärarna lyfter fram och problematiserar sin västerländska utgångspunkt. Detta görs dock med en viss reservation, och något av en deterministisk känsla. «Jag vet ju vad jag vet, beroende på vad jag har varit med om. Och jag kan inte låtsas om något annat» säger exempelvis en lärare. Detta uttalande och liknande ovan skulle kunna ses som legitimeringar av status quo. De ger uttryck för en medvetenhet om att undervisningen behöver andra perspektiv, men däremot inte för den normförändrande handlingsaspekten som är en del av den normkritiska pedagogiken. Normkritik går ut på att synliggöra normer för att sedan kunna förändra dem, och där tror jag vi som danslärare har ett stort arbete kvar att göra. 


\section{Sammanfattande diskussion Håll koll på perspektiven}

I undersökningen framkommer ett tydligt historiografiskt perspektiv hos lärarna, där olika typer av synliggörande frågor kring förutsättningarna för historieskrivningen lyfts fram. Lärarna poängterar att historieskrivningar är icke-objektiva konstruktioner som kan förändras och som påverkas av när, hur, varför och av vem de skrevs ner. Viktiga beståndsdelar i undervisningen är att förhålla sig källkritisk, det vill säga att ställa de synliggörande frågorna till historieskrivningarna, och att presentera olika perspektiv på historien. Min uppfattning är att perspektiv är ett begrepp som lärarna anser användbart för att förtydliga de många lager som skiljer det förflutna från historieskrivningen. För att det verkligen ska kunna vara krafffullt verktyg för att främja kritisk granskning av historieskrivningar tror jag dock att begreppet skulle behöva lite omsorg: förslagsvis någon typ av analytiskt ramverk som tydliggör att det är många olika personers perspektiv i många olika led som är med och skapar vår förståelse av historien. För begreppet perspektiv är användbart, och förmågan att anta många olika perspektiv är en viktig beståndsdel av kritiskt tänkande inom historieämnet (Nygren et. al. 2019).

\section{Normkritiken beho̊vs - o̊verallt}

Även det normkritiska perspektivet är närvarande i min studie. Flera av lärarna synliggör exempelvis sin egen utgångspunkt och sina begränsningar, och beskriver hur de arbetar med kritiska perspektiv som synliggör normer och maktstrukturer främst i förhållande till det västerländska perspektivet i undervisningen. Att positionera sig själv kan vara obekvämt och kräver mod, men för att ett normkritiskt perspektiv verkligen ska ha en förändrande verkan räcker det inte att bara konstatera och synliggöra vilka normer som dominerar undervisningen. Man måste också ta steget och ändra sin undervisning. I Sverige, ett historiskt homogent land, finns inte samma tydliga fokus på identitet och representation i historieundervisningen som i länder med tydliga motsättningar mellan olika kulturella grupper. Idag har dock var fjärde elev i grund- och gymnasieskolan utländsk bakgrund, och inom historiedidaktikforskningen framhålls det faktum att historieämnet förmedlar en kanon som inte är förankrad i elevernas identitet som ett problem (Skolverket u.å.b). Även om det estetiska programmets dansinriktningar tenderar att vara relativt homogena, så är detta ingen orsak att inte ifrågaä̈tta maktstrukturerna - tvärtom. McCarthy-Brown (2017) skriver att man inom högskolevärlden ofta har inställningen att när väl studenter och lärare med olika bakgrund knyts till institutionen så kommer allt lösa sig. Så är det dock inte, tvärtom blir problemen ännu tydligare när personer som avviker från mallen kliver in. Ett normkritiskt arbetssätt är därför viktigt i alla sammanhang, oavsett elevernas bakgrund. Detta visar inte minst debatten kring strukturell rasism inom Stockholms konstnärliga högskola (SKH) det senaste året, och de utmaningar som finns när det kommer till representation i den västerländska scenkonstdansen. Dessa utmaningar finns även hos de estetiska programmens dansinriktningar.

\section{Bryt upp kanon}

I min undersökning är det tydligt att det finns en kanon bestående av den västerländska scenkonstdansens historia, som för många lärare är så självklar att den inte ens upplevs som en kanon. En bredare blick på dansens historia behövs för att utmana det västerländska perspektivet och öppna upp för andra erfarenheter i dansen. McCarthy-Brown (2007) menar att diversifying content, att inkludera innehåll från annat än majoritetskulturen, är en metod som kan användas för att främja kulturell mångfald. Inom den normkritiskapedagogiken framhåller man dock att kan finnas en fara i att bara addera alternativt, normkritiskt material, då detta snarare kan förstärka än ifrågasätta den normativa huvudberättelsen (ex. Björkman 2010). Man måste alltså samtidigt ifrågasätta vilka mekanismer som skapar normen och kanon. 
Björkman (2010) skriver dock att det finns en konflikt mellan att som lärare ge kunskap om ett aktuellt kulturarv och samtidigt en normkritisk möjlighet att utmana detta. Enligt läroplanen ska varje elev få «kunskaper om och insikt i centrala delar av det svenska, nordiska och västerländska kulturarvet» (Gy11 2011, 10). Den västerländska scendansens historia kan ses som ett exempel på detta, och man måste därför som lärare hitta strategier för att ifrågasätta normen inom denna kanon. Även Carter (2007) framhåller att det ideala vore att kunna medvetandegöra alternativa historier inom det givna ramverket. Hon menar dock att det är svårt, eftersom mycket av den berättade danshistorien inte hanterar motsägelser. Det finns dock gott om forskning på danshistoriefältet idag som ifrågasätter de traditionella narrativen. Detta är alltså möjligt, men det kräver tid att sätta sig in i. Och att tiden är en bristvara framkommer i min undersökning, både tid till förberedelser och klassrumstid med eleverna.

\section{Lår med eleverna}

Jag tror att vi alla som är lärare kan bli bättre på att bredda vårt material och synliggöra hur urvalet bidrar till inkludering och exkludering. För det finns inget neutralt innehåll, allt är «kontaminerat». En utmaning för oss som lärare att inte bara granska betingelserna för hur historia skapas, utan också ifrågasätta och förändra de strukturer som skapar «värdefull» kunskap. Detta kan bland annat göras genom att lämna de välkända, begripliga berättelserna för verklighetens virrvarr. Och att bjuda in eleverna i undersökandet, och lära tillsammans med dem. För det förflutna består inte av linjära berättelser och välavgränsade epoker som hakar i varandra. Det förflutna är mångfacetterat och motsägelsefullt. Och genom att släppa de tydliga berättelserna, släppa kanon, kan vi också öppna upp för en mindre normstyrd undervisning. Frågor att ständigt ställa sig är: vilka normer ger denna text/bild/verk/rörelse uttryck för, och vilka normer är jag själv påverkad av när jag förstår den här informationen som jag gör? Vilka andra, alternativa berättelser finns det runtomkring? Målet borde vara att inte låta detta bli en övning bland många andra, utan ett självklart sätt att se på världen.

\section{Referenser}

Björkman, Lotta. 2010. «En skola i frihet - med 'misstagens hjälp'» I Normkritisk pedagogik: Makt, lärande och strategier för förändring, redaktörer Bromseth, Janne och Darj, Frida, 155-182. Uppsala: Uppsala universitet.

Bryman, Alan. 2018. Sambällsvetenskapliga metoder. 3. uppl., Johanneshov: MTM.

Carter, Alexandra. 2004a. «Destabilising the Discipline: Critical Debates about Dance History and Their Impact on the Study of Dance.» I Rethinking Dance History: A Reader, redaktör Carter, Alexandra, 10-19. London and New York: Routledge.

Carter, Alexandra. 2004b. «Interacting with History: Reflections on Philosophy and the Pedagogy of Dance History.» Research in Dance Education 5 (2): 113-125.

Carter, Alexandra. 2007. «Dance History Matters in British Higher Education.» Research in Dance Education 8 (2): 123-137.

Gy11. 2011. Läroplan, examensmål och gymnasiegemensamma ämnen för gymnasieskola 2011. Stockholm: Skolverket.

Hammergren, Lena. 2009. Dans och historiografiska reflektioner. Studs: Stockholm.

Huxley, Michael. 2012. «IIts a Different Way of Thinking about History, isn't It?': Student Perspectives on Learning Dance History.» Research in Dance Education 13 (3): 279-300. 
Järvinen, Hanna. 2009. «Dance of the Past in the Present: Teaching a Metahistory». Congress on Research in Dance, 2009 Conference Proceedings: Global Perspectives on Dance Pedagogy: Research and Practise. Leicester, Storbritannien 25-27 juni 2009: 234-40.

Karlsson, Per-Arne. 2014. Undervisning och lärande $i$ historia: ett kreativt rum för narrativ kompetens. Stockholm: Acta Universitatis Stockholmiensis.

Larsson, Kristoffer. 2013. Kritiskt tänkande $i$ grundskolans sambällskunskap: en fenomenografisk studie om manifesterat kritiskt tänkande $i$ sambällskunskap hos elever $i$ årskurs 9. Diss. Göteborg: Göteborgs universitet.

Lévesque, Stéphane. 2008. Thinking historically: educating students for the twenty-first century. Toronto, Buffalo, London: University of Toronto Press.

Lundman, Berit och Hällgren Graneheim, Ulla. 2017. «Kvalitativ innehållsanalys.» I Tillämpad kvalitativ forskning inom bälso- och sjukvard, redaktörer Höglund-Nielsen, Birgitta och Granskär, Monica, 219-232. Johanneshov: MTM.

McCarthy-Brown, Nyama. 2017. Dance Pedagogy for a Diverse World: Culturally Relevant Teaching in Theory, Research and Practice. Jefferson: McFarland \& Company, Inc., Publishers.

Nygren, Tomas, Haglund, Jesper, Samuelsson, Robin, af Geijerstam, Åsa och Prytz, Johan. 2018. «Critical Thinking in National Tests across Four Subjects in Swedish Compulsory School.» Education Inquiry 10 (1): 56-75. https://doi.org/10.1080/2 0004508.2018.1475200.

\section{BIOGRAPHY}

Saga Samuelson is a certified teacher of dance and history for upper secondary school. She also has a BA in History and Dance and Theater studies from Stockholm University. This article is
Randall, Tresa. 2009. «Teaching Dancers to Think Historically: Multidiciplinarity in Dance History Pedagogy.» Congress on Research in Dance, 2009 Conference Proceedings: Global Perspectives on Dance Pedagogy: Research and Practise. Leicester, Storbritannien 25-27 juni 2009: 248-253.

Skolverket. 2014. Främja, förebygga, upptäcka och àtgärda. Hur skolan kan arbeta mot trakasserier och kränkningar. Stockholm: Skolverket.

Skolverket. 2020. «Källkritik i gymnasieskolan.» Besökt 29 april 2020. https://www.skolverket.se/ skolutveckling/inspiration-och-stod-i-arbetet/ stod-i-arbetet/kallkritik-i-gymnasieskolan

Skolverket. u.å.a. «Ämnesplan för dansteori.» Besökt 1 april 2020. https:/www.skolverket. se/undervisning/gymnasieskolan/laroplanprogram-och-amnen-i-gymnasieskolan/ gymnasieprogrammen/amne?url=1530314731\% 2Fsyllabuscw\%2Fjsp\%2Fsubject.htm\%3FsubjectC ode\%3DDAE\%26courseCode\%3DDAEDAT0\%26tos \%3Dgy\&sv.url=12.5dfee44715d35a5cdfa92a3\#an chor_DAEDAT0.

Skolverket. u.å.b. «Att förstå sig själv och sin omvärld: Samhällskunskap, historia, religion och geografi.» Stockholm: Skolverket. https://www.skolverket.se/getFile?file $=3137$.

Sörensdotter, Renita. 2010. «En störande, utmanande och obekväm pedagogik $0 \mathrm{~m}$ queerteoriernas relevans för en normbrytande undervisning.» I Normkritisk pedagogik: Makt, lärande och strategier för förändring, redaktörer Bromseth, Janne och Darj, Frida, 135-154. Uppsala: Uppsala universitet.

based on her thesis from the Teacher Education Programme in Dance at Stockholm University of the Arts (SKH).

saga.samuelson@gmail.com 